\title{
Effects of replacing meat with soyabean in the diet on sex hormone concentrations in healthy adult males
}

\author{
Raymundo C. Habito ${ }^{1}$, Joseph Montalto ${ }^{2}$, Eva Leslie ${ }^{3}$ and Madeleine J. Ball ${ }^{1}$ \\ ${ }^{1}$ School of Biological and Chemical Sciences, Deakin University, Melbourne, Australia \\ ${ }^{2}$ Department of Clinical Biochemistry, Royal Children's Hospital, Melbourne, Australia \\ ${ }^{3}$ School of Health Sciences, Deakin University, Melbourne, Australia
}

(Received 30 March 1999 - Revised 21 February 2000 - Accepted 24 April 2000)

\begin{abstract}
A randomised crossover dietary intervention study was performed to evaluate the effects of replacing meat protein in the diet with a soyabean product, tofu, on blood concentrations of testosterone, dihydrotestosterone, androstanediol glucuronide, oestradiol, sex hormone-binding globulin (SHBG), and the free androgen index (total testosterone concentration/SHBG concentration $\times 100$; FAI). Forty-two healthy adult males aged $35-62$ years were studied. Diets were isoenergetic, with either $150 \mathrm{~g}$ lean meat or $290 \mathrm{~g}$ tofu daily providing an equivalent amount of macronutrients, with only the source of protein differing between the two diets. Each diet lasted for 4 weeks, with a 2-week interval between interventions. Fasting blood samples were taken between 07.00 and 09.30 hours. Urinary excretion of genistein and daidzein was significantly higher after the tofu diet $(P<0 \cdot 001)$. Blood concentrations of sex hormones did not differ after the two diets, but the mean testosterone:oestradiol value was $10 \%$ higher $(P=0.06)$ after the meat diet. SHBG was $3 \%$ higher $(P=0 \cdot 07)$, whereas the FAI was $7 \%$ lower $(P=0 \cdot 06)$, after the tofu diet compared with the meat diet. There was a significant correlation between the difference in SHBG and testosterone:oestradiol and weight change. Adjusting for weight change revealed SHBG to be $8.8 \%$ higher on the tofu diet (mean difference $3(95 \%$ CI 0.7, 5.2) nmol/l; $P=0.01)$ and testosterone:oestradiol to be significantly lower, $P=0.049)$. Thus, replacement of meat protein with soyabean protein, as tofu, may have a minor effect on biologically-active sex hormones, which could influence prostate cancer risk. However, other factors or mechanisms may also be responsible for the different incidence rates in men on different diets.
\end{abstract}

\section{Meat: Soyabean: Sex hormones}

Prostate disease is being increasingly diagnosed in many developed countries. Benign enlargement of the prostate may cause urethral obstruction, discomfort and urinary problems, while prostate cancer has become a major cause of death among older men in 'Westernised' populations (Muir et al. 1991). However, the precise aetiological factors have not been clearly established.

Both genetic and environmental factors have been implicated in prostate carcinogenesis (Meikle \& Stanish, 1982; Whittemore et al. 1995). Although latent prostate tumours have a similar incidence throughout the world (Akazaki \& Stemmerman, 1973; Breslow et al. 1977), international comparisons of invasive prostate cancer rates suggest that lifestyle factors, including the diet, may contribute to the progression of the disease (Armstrong \& Doll, 1975; Zaridze et al. 1985; Muir et al. 1991). The rates of prostate cancer increase among men who migrate from a country of low incidence rates to one with high incidence rates (Shimizu et al. 1991; Yu et al. 1991; Grulich et al. 1995) and this increase could be due to their adoption of a Western-style diet.

The consumption of animal products, especially the intake of fat (Slattery et al. 1990; Giovannucci et al. 1993), red meat (Talamini et al. 1986; Giovannucci et al. 1993) and some dairy products (Talamini et al. 1986; Snowdon, 1988), has been associated with an increased risk for prostate cancer. In contrast, prostate cancer rates are low in most Asian countries, where soyabean products are frequently consumed, and it has been proposed that lower disease rates might be due, at least in part, to protective effects of soyabean consumption (Adlercreutz, 1990) and of other dietary and lifestyle factors.

Prostate disease increases with age, and is considered to be dependent on sex hormones, particularly androgens

\footnotetext{
Abbreviations: adiol-G, androstanediol glucuronide; DHT, dihydrotestosterone; FAI, free androgen index; SHBG, sex hormone-binding globulin. * Corresponding author: Professor Madeleine Ball, fax +6139251 7048, email mjbikr@deakin.edu.au
} 
(Noble, 1977; Zumoff et al. 1982). In the prostate, testosterone is acted upon by the enzyme $5 \alpha$-reductase and converted to dihydrotestosterone (DHT), a more potent androgen that regulates intraprostatic metabolism (Coffey, 1986). Increased exposure of the prostate to DHT is associated with increased tissue growth (Meikle et al. 1980). DHT is metabolised to androstanediol and these two androgens have been measured in plasma (Kinouchi \& Horton, 1974; Horton et al. 1982). Although 5 $\alpha$-reductase is a tissue enzyme, its activity has been assessed indirectly through the measurement of serum androstanediol glucuronide (adiol-G; Horton et al. 1982). The balance between androgens and oestrogens has also been suggested as a possible influence on prostatic function and on the development of prostate disease (Hammond, 1978; Partin et al. 1991; Wilding, 1995). Both the biological activity and the metabolic clearance of these hormones are strongly influenced by sex hormone-binding globulin (SHBG), which reversibly binds the steroid hormones with different affinities (Burke \& Anderson, 1972; Anderson, 1974; Dunn et al. 1981). It is the small proportion of unbound sex hormones in the circulation that is biologically active (Mahoudeau et al. 1971).

The role of sex hormone metabolism on prostate disease has been explored in a few cross-sectional and clinical investigations. Lower adiol-G concentrations in Asian men than in Caucasian and African-American men have been reported (Lookingbill et al. 1991; Ross et al. 1992), suggesting that variations in $5 \alpha$-reductase activity may explain some differences in prostate cancer rates in populations at different risk for the disease. Pharmacological inhibition of $5 \alpha$-reductase enzyme using the drug finasteride has resulted in symptomatic relief and reduction of the prostatic volume in patients with benign prostatic hypertrophy (Gormley et al. 1992), and the role of finasteride in the prevention of prostate cancer is also being investigated (Brawley et al. 1994). Certain dietary constituents may mediate prostate cancer growth via hormonal (Hutchinson, 1976) and other mechanisms. Hence, any dietary component that influences the amount of biologically-available androgens within the prostate gland is of interest.

Soyabeans and processed soyabean products contain isoflavones such as genistin and daidzin (Coward et al. 1993), phyto-oestrogens that possess weak oestrogenic properties (Shutt \& Cox, 1972). An in vitro study has demonstrated that genistein inhibits the growth of prostate tumour cells (Peterson \& Barnes, 1993). The finding that genistein may also inhibit $5 \alpha$-reductase activity in vitro (Evans et al. 1995) suggests that soyabean consumption might explain some differences in $5 \alpha$-reductase activity between populations, as measured by serum concentrations of adiol-G (Lookingbill et al. 1991; Ross et al. 1992), and the subsequent differences in prostate cancer rates.

A vegetarian diet has been associated with increased circulating levels of SHBG (Belanger et al. 1989; Key et al. 1990). In addition, in vitro data suggest that genistein may increase hepatic SHBG production (Mousavi \& Adlercreutz, 1993; Loukovaara et al. 1995). Any effects of dietary constituents on SHBG levels are likely to affect sex hormone metabolism through its influence on hormone binding and clearance. A small number of intervention studies have reported effects of various nutrients on endogenous sex hormone levels in men. Decreased intake of fat (Hamalainen et al. 1984; Dorgan et al. 1996), increased dietary fibre (Dorgan et al. 1996) and changes to a vegetarian diet (Raben et al. 1992) have resulted in lower plasma androgen levels. Previous diet-intervention studies have involved simultaneous changes in various dietary components, and there is little information available on the specific effects of soyabean consumption on sex hormone concentrations in healthy adult males.

In this intervention study, meat protein in the diet of freeliving male volunteers was replaced with protein from a soyabean product, tofu, to investigate whether soyabean consumption may influence endogenous levels of sex hormones and their binding protein in such a way as to reduce overall androgenic activity.

\section{Subjects and methods}

Healthy omnivorous Caucasian males between the ages of 35 and 62 years were recruited through local contacts and newspaper advertisements. Individuals with symptoms or previous diagnosis of prostate disease or other illnesses, with alcohol intakes exceeding $10 \%$ total daily energy intake, or those taking long-term medications that might affect sex hormone concentrations, were not included. Athletes who train regularly for competitive sport, and obese men with a BMI $>35 \mathrm{~kg} / \mathrm{m}^{2}$, were also excluded from the study. The study protocol was approved by the Deakin University Ethics Committee, and written informed consent was obtained from all the participants.

A randomised crossover design was used. Before the start of the study, participants completed a $7 \mathrm{~d}$ weighedfood record on their usual diets. Each participant was then randomly assigned to one of the two diets for a period of 4 weeks, subsequently resuming the usual diet for 2 weeks as a 'wash-out period' before being assigned to the other diet for a further 4 weeks. The two diets provided similar amounts of energy, protein, carbohydrate, fat, dietary fibre and alcohol, differing only in the source of dietary protein. The meat diet included $150 \mathrm{~g}$ lean red meat/d (raw weight, but eaten as cooked product). The tofu diet contained $290 \mathrm{~g}$ tofu/d (raw weight), containing about $35 \mathrm{~g}$ soyabean protein, in specially-prepared meals and biscuits, and subjects were allowed not more than one serving of chicken or fish per week. Additional amounts of butter (5 g), animal fat (lard; $5 \mathrm{~g}$ ) and olive oil (8 ml) were used to compensate for the lower fat content of tofu compared with meat and to minimise differences in intake of total, saturated, monounsaturated and polyunsaturated fat during the two diets. Tofu was provided and purchased from a single source (Blue Lotus Foods, Kilsyth, Victoria, Australia). Other aspects of the diet were kept as constant as possible, and subjects were also asked to keep their physical activity pattern as similar as possible during the two diets. Subjects were contacted at least weekly to be given support and advice for any difficulties encountered in order to improve compliance.

Each subject completed a $7 \mathrm{~d}$ weighed-diet record during the last week of each diet period. Diet records were 
analysed using the software System for Online Dietary Analysis version 5 (SODA, Cottesloe, WA, Australia) that used updated nutrient composition data for Australian foods.

Height and weight of each participant was measured and BMI calculated before and after each diet period. Venous blood samples were collected before the study and on two occasions $3 \mathrm{~d}$ apart at the end of each diet after an overnight fast between 07.00 and 09.30 hours at a uniform time for each subject to minimise variation in hormone concentrations due to diurnal rhythms. Serum was separated at $4^{\circ} \mathrm{C}$ and stored at $-80^{\circ} \mathrm{C}$ for later analysis. Commercial radioimmunoassay (RIA) kits were used to measure serum concentrations of total testosterone (Medgenix, Biosource, Belgium), DHT, adiol-G (Diagnostics Systems Laboratories Inc, TX, USA), and oestradiol (Spectria, Orion Diagnostica, Espoo, Finland). Serum SHBG was analysed by immunoradiometric assay (Spectria). All samples from the same subject were analysed in a single batch. The intra-assay $\mathrm{CV}$ were less than $6 \%$ for testosterone and SHBG, and less than $10 \%$ for DHT, adiol$\mathrm{G}$ and oestradiol. The free androgen index (total testosterone concentration/SHBG concentration $\times 100$; FAI) and testosterone:oestradiol were calculated. Samples from eleven subjects were assayed for cholesteryl ester-fatty acids using GC after extraction from serum according to the method described by Sinclair et al. (1987).

A $24 \mathrm{~h}$ urine collection was completed at the end of each diet period and portions were immediately frozen at $-20^{\circ} \mathrm{C}$. Genistein and daidzein were isolated by reversephase HPLC (Shimadzu system LC10A; Shimadzu Scientific Instruments Pty Ltd, Melbourne, Australia) after deconjugation using glucuronidase (Sigma Chemical Company, St Louis, MO, USA) and extraction with diethyl ether following a method developed by Eldridge (1982). The urinary creatinine concentration was measured using a Hitachi 704 autoanalyser (Hitachi Ltd, Tokyo, Japan)

Sample size was calculated to provide an $80 \%$ power of detecting a $10 \%$ difference in hormone levels. Statistical analyses were performed using the Statistical Package for the Social Sciences version 7.5 (SPSS Inc. Chicago, IL, USA). Mean hormone values from two separate blood samples collected at the end of each diet were used for analysis, as these values were not significantly different. Non-normally-distributed data were log transformed. The general linear model was used to compare hormone results at the end of the two diet periods, taking carry-over effects into consideration (Fleiss, 1986). As there were no carryover effects for any of the variables, this factor was disregarded in the analysis of the diet effects. Mean results for each diet were compared using the paired $t$ test for normally-distributed data or the Wilcoxon signed-rank test for data that were not normally distributed after log transformation. As there was a significant correlation between weight change and SHBG $(r=0 \cdot 36)$, the paired difference was adjusted using multiple linear regression.

\section{Results}

Of the forty-five subjects enrolled in the study, three were excluded before data analysis as they were unable to
Table 1. Dietary intakes of healthy adult males when receiving the lean meat and tofu diets ${ }^{\ddagger}$

(Values are means and standard deviations for forty-two subjects)

\begin{tabular}{|c|c|c|c|c|}
\hline & \multicolumn{2}{|c|}{ Lean-meat diet } & \multicolumn{2}{|c|}{ Tofu diet } \\
\hline & Mean & SD & Mean & SD \\
\hline Energy (MJ) & 9.6 & 0.3 & 9.5 & 0.3 \\
\hline Protein $(\mathrm{g})$ & $96 \cdot 7$ & $3 \cdot 1$ & $93 \cdot 2$ & $2 \cdot 9$ \\
\hline Fat $(\mathrm{g})$ & 84.5 & 3.4 & 81.9 & 3.4 \\
\hline $\operatorname{SF}(g)$ & 33.5 & 1.4 & $31 \cdot 8$ & 1.5 \\
\hline MF (g) & 31.0 & 1.4 & 29.2 & 1.3 \\
\hline$P F(g)$ & $12 \cdot 7$ & 0.7 & $13 \cdot 2$ & 0.7 \\
\hline$P: S$ & 0.4 & 0.1 & $0.42^{*}$ & 0.2 \\
\hline Carbohydrate (g) & $262 \cdot 1$ & $56 \cdot 7$ & $260 \cdot 9$ & 64.6 \\
\hline Cholesterol (mg) & $253 \cdot 2$ & $11 \cdot 2$ & 189.5††† & $16 \cdot 3$ \\
\hline Fibre (g) & $28 \cdot 0$ & 1.4 & $26 \cdot 6$ & $1 \cdot 2$ \\
\hline Alcohol (g) & $16 \cdot 9$ & 21.4 & $17 \cdot 9$ & $21 \cdot 0$ \\
\hline Protein (\% energy) & $17 \cdot 2$ & 0.3 & $16 \cdot 9$ & 0.3 \\
\hline Carbohydrate (\% energy) & 43.7 & 0.8 & 44.0 & 0.8 \\
\hline Fat (\% energy) & $32 \cdot 4$ & 0.8 & 31.9 & 0.8 \\
\hline SF (\% energy) & $12 \cdot 9$ & 0.5 & $12 \cdot 4$ & 0.4 \\
\hline MF (\% energy) & $11 \cdot 8$ & 0.3 & 11.5 & 0.4 \\
\hline PF (\% energy) & 4.8 & 0.2 & $5 \cdot 1$ & 0.2 \\
\hline Alcohol (\% energy) & 4.9 & 0.8 & 5.4 & 0.9 \\
\hline
\end{tabular}

SF, saturated fat; MF, monounsaturated fat; PF, polyunsaturated fat; $\mathrm{P}: \mathrm{S}$ polyunsaturated:saturated fat.

Mean value was significantly different from that for lean-meat diet (paired $t$ test): ${ }^{\star} P=0.047$.

Mean value was significantly different from that for lean-meat diet (paired test):

‡ For details of diets, see p. 558 .

complete the prescribed diets. Thus, data were analysed on forty-two men, of mean age 45.7 (SD 7.6) years and mean BMI $26 \cdot 2(\mathrm{SD} 3 \cdot 3) \mathrm{kg} / \mathrm{m}^{2}$ at baseline. The mean intakes of energy, protein, carbohydrate, total and saturated fat, monounsaturated fat, polyunsaturated fat, fibre and alcohol did not differ during the meat and tofu diets (Table 1). The tofu contained $0.29 \mathrm{mg}$ genistin/g and $0.12 \mathrm{mg}$ diadzin $/ \mathrm{g}$. The mean body weights of the subjects after the meat and tofu diets were 83.1 (SD 10.8) $\mathrm{kg}$ and 83.5 (SD 11.3) kg respectively $(P=0.05)$.

Urinary concentrations of genistein and daidzein are shown in Table 2. Urine samples were available for thirtyone subjects and all showed greatly increased excretion on the tofu diet. The serum cholesteryl ester-fatty acid concentrations for individual saturated and monounsaturated fatty acids did not differ after the two diets.

Hormone concentrations after the two diets are shown in Table 3. Serum testosterone, DHT, adiol-G and oestradiol did not differ significantly after the two diets. SHBG was

Table 2. Urinary concentrations of genistein and daidzein for healthy adult males receiving the lean-meat and tofu diets $\dagger$

(Values are means and standard deviations for thirty-one subjects)

\begin{tabular}{|c|c|c|c|c|}
\hline & \multicolumn{2}{|c|}{ Lean-meat diet } & \multicolumn{2}{|c|}{ Tofu diet } \\
\hline & Mean & SD & Mean & SD \\
\hline Genistein:ng/ $\mu \mathrm{mol}$ creatinine & $12 \cdot 4$ & $11 \cdot 2$ & $201 \cdot 8^{\star \star \star}$ & $195 \cdot 9$ \\
\hline$\mu \mathrm{mol} / 24 \mathrm{~h}$ & 0.3 & 0.5 & $2 \cdot 9^{* * *}$ & $3 \cdot 0$ \\
\hline Daidzein:ng/ $\mu \mathrm{mol}$ creatinine & $20 \cdot 3$ & $23 \cdot 4$ & $401 \cdot 3^{* * \star}$ & $254 \cdot 0$ \\
\hline$\mu \mathrm{mol} / 24 \mathrm{~h}$ & 0.5 & $1 \cdot 0$ & $6 \cdot 1^{* * *}$ & 5.4 \\
\hline
\end{tabular}

Mean values were significantly different from those for the lean-meat diet (paired $t$ test): ${ }^{\star \star \star} P<0.001$.

† For details of diets and procedures, see p. 558 
Table 3. Serum hormone values for healthy adult males after 4 weeks on the lean-meat and tofu diets (Values are means and $95 \% \mathrm{Cl}$ for forty-two subjects)

\begin{tabular}{|c|c|c|c|c|c|c|c|}
\hline & \multicolumn{2}{|c|}{ Lean-meat diet } & \multicolumn{2}{|c|}{ Tofu diet } & \multicolumn{3}{|c|}{ Tofu diet - lean meat diet } \\
\hline & Mean & $95 \% \mathrm{Cl}$ & Mean & $95 \% \mathrm{Cl}$ & Difference & $95 \% \mathrm{Cl}$ & $P$ value \\
\hline Testosterone (nmol/l) & $15 \cdot 4$ & $13 \cdot 7,17 \cdot 1$ & $15 \cdot 5$ & $13 \cdot 8,17 \cdot 1$ & $0 \cdot 1$ & $-0.6,0.8$ & $0.94 \S$ \\
\hline Dihydrotestosterone $(\mathrm{nmol} / \mathrm{l})$ & 1.08 & $0.93,1.24$ & $1 \cdot 13$ & $0.96,1.31$ & 0.05 & $-0.02,0.12$ & $0.22 \|$ \\
\hline Androstanediol glucuronide (nmol/l) & $16 \cdot 6$ & $14.4,18 \cdot 8$ & $17 \cdot 9$ & $15 \cdot 4,20 \cdot 4$ & 1.3 & $0.09,2.4$ & $0.08 \|$ \\
\hline Sex hormone-binding globulin (SHBG; nmol/l) & 33.2 & $28 \cdot 6,37 \cdot 7$ & $34 \cdot 3$ & $29 \cdot 6,38 \cdot 9$ & $1 \cdot 1$ & $-0.08,2.3$ & 0.079 \\
\hline Adjusted value & & & & & 3.0 & $0 \cdot 7,5 \cdot 2$ & 0.01 \\
\hline Free androgen index (total testosterone/SHB6 $\times 100$ ) & $50 \cdot 0$ & $44 \cdot 8,55 \cdot 2$ & $46 \cdot 7$ & $42 \cdot 0,51 \cdot 5$ & $-3 \cdot 3$ & $-6 \cdot 8,0 \cdot 2$ & $0.06 \rrbracket$ \\
\hline Oestradiol (pmol/l) & 69.6 & $60 \cdot 6,78 \cdot 6$ & 74.2 & $65 \cdot 6,82 \cdot 9$ & $4 \cdot 6$ & $-3 \cdot 0,12 \cdot 2$ & $0 \cdot 13 \|$ \\
\hline Testosterone:oestradiol & 248.9 & $210.4,287.5$ & $223 \cdot 3$ & $194 \cdot 6,252 \cdot 0$ & $-25 \cdot 6$ & $-51 \cdot 0,0.3$ & $0.06 \|$ \\
\hline Adjusted value $†$ & & & & & $-28 \cdot 0$ & $-53 \cdot 0,-2 \cdot 6$ & 0.049 \\
\hline
\end{tabular}

* For details of diets and procedures, see p. 558.

$\dagger$ Values after adjusting for weight change using multiple linear regression.

¥ Mean difference of untransformed results.

$\S$ Difference $=0$, based on Wilcoxon signed-ranks test

|| Difference $=0$, based on paired $t$ test of log-transformed values.

ๆ Difference $=0$, based on paired $t$ test of untransformed values.

$3 \%$ higher after the tofu diet than after the lean meat diet $(P=0.07)$, and the FAI was $7 \%$ lower on the tofu diet $(P=0.06)$. The mean serum oestradiol concentrations did not differ significantly after the two diets, although the testosterone:oestradiol tended to be higher on the meat diet $(P=0.06)$. There was a significant correlation between the difference in SHBG and testosterone:oestradiol and weight change. The paired difference adjusted for weight change by multiple linear regression showed the mean SHBG to be $8.8 \%$ higher on the tofu, and testosterone:oestradiol to be lower.

\section{Discussion}

The present study was designed to replace dietary protein from meat with soyabean protein, while keeping the intake of other nutrients as similar as possible. Tofu was chosen, as it is easy to prepare and is adaptable to many recipes. Previous diet-intervention studies that investigated the effects of soyabean intake on hormonal responses involved female subjects (Cassidy et al. 1994; Petrakis et al. 1996). To our knowledge, this is the first intervention study reporting the effects of a soyabean diet on sex hormone levels and $5 \alpha$-reductase activity in men. Urinary concentrations of the isoflavones genistein and daidzein increased significantly after the tofu diet, and the values we obtained were within the range of reported values in Japanese men consuming a traditional diet (Adlercreutz et al. 1991), who are considered to be at low risk for prostate disease.

The results of the present study suggest that overall androgen activity, as measured by increased SHBG and lowered testosterone:oestrogen, may be lowered by dietary isoflavones. Other studies have reported changes in SHBG concentrations in response to dietary changes (Anderson et al. 1987; Reed et al. 1987; Key et al. 1990; Gates et al. 1996). However, the effects of other dietary factors, BMI, physical activity and other lifestyle characteristics on SHBG could not be excluded (Gates et al. 1996). The present study attempted to ensure that macronutrients and physical activity levels were constant throughout the study period by intensive contact with the participants. However, we found a small but significant $(P=0.05)$ difference in body weight on the two diets, and the results were adjusted for weight change when appropriate.

Although serum oestradiol did not differ on the two diets, the lower testosterone:oestradiol after the tofu diet is consistent with our hypothesis that a soyabean diet may result in lower androgen activity and is likely to be related to the increase in SHBG. Since SHBG has greater binding affinity to testosterone than to oestrogen (Dunn et al. 1981), an increase in circulating SHBG may alter the balance between unbound androgens and oestrogens in favour of oestrogen (Burke \& Anderson, 1972; Anderson, 1974). Serum levels of testosterone and its metabolites did not differ significantly between the two diets. The FAI had a slight tendency to be lower on the tofu diet; however, as FAI was calculated and is very sensitive to the SHBG measure, the actual changes in free hormone levels are not certain. We thus found no conclusive evidence that shortterm soyabean intake has an influence on the circulating concentrations of androgens and the activity of $5 \alpha-$ reductase, as measured by serum adiol-G. It is possible that homoeostatic mechanisms may have caused attenuation of any differences in circulating hormone levels in response to the diet changes. Furthermore, questions have been raised as to whether serum androgen levels accurately reflect hormone metabolism in prostate tissue (Rittmaster et al. 1993; Hsing, 1996) and our findings do not exclude the possibility of an effect of soyabean intake on hormone metabolism within the prostate.

Since sex hormones and SHBG may be sensitive to weight changes, the interpretation of our results was confounded by the small change in mean body weight $(0.4 \mathrm{~kg})$. The changes were not consistent with the selfreported energy intakes, which showed no major difference between the two diets. Small variations in body weight are common over several months, and some variation in energy intake and/or physical activity occurred in a few subjects, with the greatest weight alteration after changing from one diet to another. Energy intakes of all subjects, evaluated using the method described by Goldberg et al. (1991), suggested the possibility of under-reporting of energy 
intakes in a number of subjects during both diets, but no evidence that this differed between the two diets. However, the increase in urinary phyto-oestrogen excretion on the tofu diet reflects a marked increase in soyabean intake; regular feedback during the study from the highlymotivated volunteers indicates that all subjects accomplished a major change from a meat- to a soyabean-based diet with few other differences; and the cholesteryl esterfatty acids support overall compliance with the planned diets.

The biological significance of the slight reduction in the total androgen activity that results from higher SHBG concentrations in response to a soyabean diet, and whether soyabean intake over a span of many years may affect sex hormone metabolism, requires further study. The findings from a prospective study of sex hormone levels and prostate cancer risk suggest that increased levels of testosterone and low SHBG, even within normal endogenous ranges, are associated with a higher risk of prostate cancer (Gann et al. 1996), as are low levels of oestradiol. In that study there was a $35 \%$ difference in prostate cancer risk in the groups with a median SHBG of 17.6 and $25 \cdot 2 \mathrm{nmol} / \mathrm{l}$.

Asian populations start to consume soyabean products at a young age, as a regular feature of the diet. Minor hormonal changes resulting from long-term soyabean intake may confer protection against prostate cancer, in combination with other dietary or lifestyle factors. However, in vitro studies have suggested direct inhibitory effects of genistein on tumour growth through other mechanisms (Akiyama et al. 1987; Wei et al. 1993; Fotsis et al. 1995), and such effects could explain an effect of soyabean independent of hormonal influences. In reality, Asian diets differ from Western diets in more than just soyabean consumption in that they generally contain less fat and include a higher intake of cereals, vegetables and fish (Gates et al. 1996). A combination of these factors may provide long-term protection; this area warrants further epidemiological research, larger intervention studies and in vitro investigation of possible mechanisms of action.

\section{Acknowledgements}

The authors gratefully acknowledge the funding support for this study from the Australian Commonwealth Department of Veterans Affairs. Tofu was kindly provided at cost by Blue Lotus Foods, Kilsyth, Victoria, Australia. We are grateful for the expert assistance of Emma Ashton and Jane Foster in data collection and to Associate Professor Thomas Watson for his helpful comments. Dr Fabien Dalais from the Royal Women's Hospital (supervisor Professor Mark Wahlqvist) kindly undertook the phyto-oestrogen analyses, and Drs Sing Kai Lo and Iain Robertson provided expert biostatistical advice.

\section{References}

Adlercreutz H (1990) Western diet and Western diseases: some hormonal and biochemical mechanisms and associations.
Scandinavian Journal of Clinical and Laboratory Investigation 2011, 3-23.

Adlercreutz H, Honjo H, Higashi A, Fotsis T, Hamalainen E, Hasegawa T \& Okada H (1991) Urinary excretion of lignans and isoflavonoid phytoestrogens in Japanese men and women consuming a traditional Japanese diet. American Journal of Clinical Nutrition 54, 1093-1100.

Akazaki K \& Stemmerman GN (1973) Comparative study of latent carcinoma of the prostate among Japanese in Japan and Hawaii. Journal of the National Cancer Institute 50, 11371144.

Akiyama T, Ishida J, Nakagawa S, Ogawara H, Watanabe S, Itoh N, Shibuya M \& Fukami Y (1987) Genistein, a specific inhibitor of tyrosine-specific protein kinases. Journal of Biological Chemistry 262, 5592-5595.

Anderson DC (1974) Sex-hormone-binding globulin. Clinical Endocrinology 3, 69-96.

Anderson KE, Rosner W, Khan MS, New MI, Pang SY, Wissel PS \& Kappas A (1987) Diet-hormone interactions: protein/ carbohydrate ratio alters reciprocally the plasma levels of testosterone and cortisol and their respective binding globulins in man. Life Sciences 40, 1761-1768.

Armstrong B \& Doll R (1975) Environmental factors and cancer incidence and mortality in different countries with special reference to dietary practices. International Journal of Cancer 15, 617-631.

Belanger A, Locong A, Noel C, Cusan L, Dupont A, Prevost J, Caron S \& Sevigny J (1989) Influence of diet on plasma steroids and sex hormone-binding globulin levels in adult men. Journal of Steroid Biochemistry 32, 829-833.

Brawley OW, Ford LG, Thompson I, Perlman JA \& Kramer BS (1994) 5-Alpha-reductase inhibition and prostate cancer prevention. Cancer Epidemiology, Biomarkers, and Prevention 3, 177-182.

Breslow N, Chan CW, Dhom G, Drury RA, Franks LM, Gellei B, Lee YS, Lundberg S, Sparke B, Sternby NH \& Tulinius H (1977) Latent carcinoma of prostate of autopsy in seven areas. International Journal of Cancer 20, 680-688.

Burke CW \& Anderson DC (1972) Sex-hormone-binding globulin is an oestrogen amplifier. Nature 240, 38-40.

Cassidy A, Bingham S \& Setchell KD (1994) Biological effects of a diet of soy protein rich in isoflavones on the menstrual cycle of premenopausal women. American Journal of Clinical Nutrition 60, 333-340.

Coffey DS (1986) Endocrine control of normal and abnormal growth of the prostate. In Urologic Endocrinology, pp. 170195 [J Rajfer, editor]. Philadelphia, PA: W.B. Saunders.

Coward L, Barnes NC, Setchell KDR \& Barnes S (1993) The antitumor isoflavones, genistein and daidzein, in soybean foods of American and Asian diets. Journal of Agricultural and Food Chemistry 41, 1961-1967.

Dorgan JF, Judd JT, Longcope C, Brown C, Schatzkin A, Clevidence BA, Campbell WS, Nair PP, Franz C, Kahle L \& Taylor PR (1996) Effects of dietary fat and fiber on plasma and urine androgens and estrogens in men: a controlled feeding study. American Journal of Clinical Nutrition 64, 850-855.

Dunn JF, Nisula BC \& Rodbard D (1981) Transport of steroid hormones: binding of 21 endogenous steroids to both testosterone-binding globulin and corticosteroid-binding globulin in human plasma. Journal of Clinical Endocrinology and Metabolism 53, 58-68.

Eldridge AC (1982) Determination of isoflavones in soybean flours, protein concentrates, and isolates. Journal of Agricultural and Food Chemistry 30, 353-355.

Evans BA, Griffiths K \& Morton MS (1995) Inhibition of 5 alphareductase in genital skin fibroblasts and prostate tissue by 
dietary lignans and isoflavonoids. Journal of Endocrinology 147, 295-302.

Fleiss JL (1986) The Design and Analysis of Clinical Experiments. New York: John Wiley and Sons.

Fotsis T, Pepper M, Adlercreutz H, Fleischmann G, Hase T, Montesano R \& Schweigerer L (1995) Genistein, a dietaryderived inhibitor of in vitro angiogenesis. Journal of Nutrition 125, 790S-797S.

Gann PH, Hennekens CH, Ma J, Longcope C \& Stampfer MJ (1996) Prospective study of sex hormone levels and risk of prostate cancer. Journal of the National Cancer Institute 88, $1118-1126$.

Gates JR, Parpia B, Campbell TC \& Junshi C (1996) Association of dietary factors and selected plasma variables with sex hormone-binding globulin in rural Chinese women. American Journal of Clinical Nutrition 63, 22-31.

Giovannucci E, Rimm EB, Colditz GA, Stampfer MJ, Ascherio A, Chute CC \& Willett WC (1993) A prospective study of dietary fat and risk of prostate cancer. Journal of the National Cancer Institute 85, 1571-1579.

Goldberg GR, Black AE, Jebb SA, Cole TJ, Murgatroyd PR, Coward WA \& Prentice AM (1991) Critical evaluation of energy intake data using fundamental principles of energy physiology: 1. Derivation of cut-off limits to identify underrecording. European Journal of Clinical Nutrition 45, 569-581.

Gormley GJ, Stoner E, Bruskewitz RC, Imperato-McGinley J, Walsh PC, McConnell JD, Andriole GL, Geller J, Bracken BR, Tenover JS, Vaughan DE, Pappas F, Taylor A, Binkowitz B \& $\mathrm{Ng}$ J (1992) The effect of finasteride in men with benign prostatic hyperplasia. The Finasteride Study Group. New England Journal of Medicine 327, 1185-1191.

Grulich AE, McCredie M \& Coates M (1995) Cancer incidence in Asian migrants to New South Wales, Australia. British Journal of Cancer 71, 400-408.

Hamalainen E, Adlercreutz H, Puska P \& Pietinen P (1984) Diet and serum sex hormones in healthy men. Journal of Steroid Biochemistry 20, 459-464.

Hammond GL (1978) Endogenous steroid levels in the human prostate from birth to old age: a comparison of normal and diseased tissues. Journal of Endocrinology 78, 7-19.

Horton R, Hawks D \& Lobo R (1982) 3 alpha 17 betaAndrostanediol glucuronide in plasma. A marker of androgen action in idiopathic hirsutism. Journal of Clinical Investigation 69, 1203-1206.

Hsing AW (1996) Hormones and prostate cancer: where do we go from here? Journal of the National Cancer Institute 88, 10931095.

Hutchinson GB (1976) Epidemiology of prostatic cancer. Seminars in Oncology 3, 151-159.

Key TJ, Roe L, Thorogood M, Moore JW, Clark GM \& Wang DY (1990) Testosterone, sex hormone-binding globulin, calculated free testosterone, and oestradiol in male vegans and omnivores. British Journal of Nutrition 64, 111-119.

Kinouchi T \& Horton R (1974) 3 Alpha-androstanediol in human peripheral plasma. Journal of Clinical Endocrinology and Metabolism 38, 262-268.

Lookingbill DP, Demers LM, Wang C, Leung A, Rittmaster RS \& Santen RJ (1991) Clinical and biochemical parameters of androgen action in normal healthy Caucasian versus Chinese subjects. Journal of Clinical Endocrinology and Metabolism 72, 1242-1248.

Loukovaara M, Carson M, Palotie A \& Adlercreutz H (1995) Regulation of sex hormone-binding globulin production by isoflavonoids and patterns of isoflavonoid conjugation in HepG2 cell cultures. Steroids 60, 656-661.

Mahoudeau JA, Bardin CW \& Lipsett MB (1971) The metabolic clearance rate and origin of plasma dihydrotestosterone in man and its conversion to $5 \alpha$-androstanediols. Journal of Clinical Investigation 50, 1338-1344.

Meikle AW, Collier ES, Middleton RG \& Fang SM (1980) Supranormal nuclear content of 5 alpha-dihydrotestosterone in benign hyperplastic prostate of humans. Journal of Clinical Endocrinology and Metabolism 51, 945-947.

Meikle AW \& Stanish WM (1982) Familial prostatic cancer risk and low testosterone. Journal of Clinical Endocrinology and Metabolism 54, 1104-1108.

Mousavi Y \& Adlercreutz H (1993) Genistein is an effective stimulator of sex hormone-binding globulin production in hepatocarcinoma human liver cancer cells and suppresses proliferation of these cells in culture. Steroids 58, 301-304.

Muir CS, Nectoux J \& Staszewski J (1991) The epidemiology of prostatic cancer: Geographical distribution and time-trends. Acta Oncologica 30, 133-140.

Noble RL (1977) The development of prostatic adenocarcinoma in $\mathrm{Nb}$ rats following prolonged sex hormone administration. Cancer Research 37, 1929-1933.

Partin AW, Oesterling JE, Epstein JI, Horton R \& Walsh PC (1991) Influence of age and endocrine factors on the volume of benign prostatic hyperplasia. Journal of Urology 145, 405-409.

Peterson G \& Barnes S (1993) Genistein and biochanin A inhibit the growth of human prostate cancer cells but not epidermal growth factor receptor tyrosine autophosphorylation. Prostate 22, 335-345.

Petrakis NL, Barnes S, King EB, Lowenstein J, Wiencke J, Lee MM, Miike R, Kirk M \& Coward L (1996) Stimulatory influence of soy protein isolate on breast secretion in pre- and postmenopausal women. Cancer Epidemiology, Biomarkers, and Prevention 5, 785-794.

Raben A, Kiens B, Richter EA, Rasmussen LB, Svenstrup B, Micic S \& Bennett P (1992) Serum sex hormones and endurance performance after a lacto-ovo vegetarian and a mixed diet. Medicine and Science in Sports and Exercise 24, 1290-1297.

Reed MJ, Cheng RW, Simmonds M, Richmond W \& James VH (1987) Dietary lipids: an additional regulator of plasma levels of sex hormone binding globulin. Journal of Clinical Endocrinology and Metabolism 64, 1083-1085.

Rittmaster RS, Zwicker H, Thompson DL, Konok G \& Norman RW (1993) Androstanediol glucuronide production in human liver, prostate, and skin. Journal of Clinical Endocrinology and Metabolism 76, 977-982.

Ross RK, Bernstein L, Lobo RA, Shimizu H, Stanczyk FZ, Pike MC \& Henderson BE (1992) 5-Alpha-reductase activity and risk of prostate cancer among Japanese and US white and black males. Lancet 339, 887-889.

Shimizu H, Ross RK, Bernstein L, Yatani R, Henderson BE \& Mack TM (1991) Cancers of the prostate and breast among Japanese and white immigrants in Los Angeles County. British Journal of Cancer 63, 963-966.

Shutt DA \& Cox RI (1972) Steroid and phyto-oestrogen binding to sheep uterine receptors in vitro. Journal of Endocrinology 52, 299-310.

Sinclair AJ, O’Dea K, Dunstan G, Ireland PD \& Niall M (1987) Effect on plasma lipids and fatty acid composition of very low fat diets enriched with fish or kangaroo meat. Lipids 1987, 523-529.

Slattery ML, Schumacher MC, West DW, Robison LM \& French TK (1990) Food-consumption trends between adolescent and adult years and subsequent risk of prostate cancer. American Journal of Clinical Nutrition 52, 752-757.

Snowdon DA (1988) Animal product consumption and mortality because of all causes combined, coronary heart disease, stroke, diabetes, and cancer in Seventh-day Adventists. American Journal of Clinical Nutrition 48, 739-748. 
Talamini R, La Vecchia C, Decarli A, Negri E \& Franceschi S (1986) Nutrition, social factors and prostatic cancer in a Northern Italian population. British Journal of Cancer 53, 817-821.

Wei H, Wei L, Frenkel K, Bowen R \& Barnes S (1993) Inhibition of tumor promoter-induced hydrogen peroxide formation in vitro and in vivo by genistein. Nutrition and Cancer 20, 1-12.

Whittemore AS, Kolonel LN, Wu AH, John EM, Gallagher RP, Howe GR, Burch JD, Hankin J, Dreon DM, West DW, Teh C-T \& Paffenberger RS Jr (1995) Prostate cancer in relation to diet, physical activity, and body size in blacks, whites, and Asians in the United States and Canada. Journal of the National Cancer Institute 87, 652-661.

Wilding G (1995) Endocrine control of prostate cancer. Cancer Survey 23, 43-62.
Yu H, Harris RE, Gao YT, Gao R \& Wynder EL (1991) Comparative epidemiology of cancers of the colon, rectum, prostate and breast in Shanghai, China versus the United States. International Journal of Epidemiology 20, 76-81.

Zaridze DG, Muir CS \& McMichael AJ (1985) Diet and cancer: value of different types of epidemiological studies. Nutrition and Cancer 7, 155-166.

Zumoff B, Levin J, Strain GW, Rosenfeld RS, O’Connor J, Freed SZ, Kream J, Whitmore WS, Fukushima DK \& Hellman L (1982) Abnormal levels of plasma hormones in men with prostate cancer: evidence toward a 'two-disease' theory. Prostate 3, 579-588. 